\title{
Performance assessment of triangular Obstacles mounted Solar Air Heater Using Taguchi Method
}

\author{
Ashwni*, Sachin Gupta and Ramakant Rana \\ Department of Mechanical and Automation Engineering, Maharaja Agrasen Institute of Technology, Delhi, India \\ * Corresponding Author : ashwanigoyal617@gmail.com
}

\begin{abstract}
In this experimental work, the investigation about the impact of the geometrical dispositions of the triangular obstacles on the performance parameters such as pressure drop and thermal efficiency. A number of input parameters affects the performance of the system. These input parameters are the heat flux, mass flow rate $(=0.01$ to $0.02 \mathrm{~kg} / \mathrm{s})$, obstacles' height, h from $22 \mathrm{~mm}$ to $37.5 \mathrm{~mm}$, their cross-stream wise pitch (Ly $=56$ to $206 \mathrm{~mm}$ ), their angle of inclination with the vertical plane $\left(\Theta=30^{\circ}-90^{\circ}\right)$, and stream wise pitch $(\mathrm{Lx}=30$ to $70 \mathrm{~mm})$. Moreover, an optimum set of input parameters is determined using the statistical modeling of the operating conditions by the Taguchi technique.
\end{abstract}

Keywords: Solar air heater; Triangular obstacles; Taguchi method.

\section{INTRODUCTION}

The solar air heater (SAH) is used to absorb the sun's irradiation using an absorber plate that gets heated eventually. Then, this heat is transferred to air passing through the solar air heater. As a result, heated air can be utilized as per the requirement like drying or space heating. Several investigations have been accomplished to determine the impact of various shapes installed on the absorber plate on pressure drop and heat transfer for airflow through SAH. (Choudhury and Garg, 1991) carried out a detailed parametric analysis of both flat plate and corrugated one solar air heaters (SAHs) using five unique configurations. The parametric examination primarily centered around the effect of the velocity of airflow on thermal efficiency, pressure drop, and increase in temperature of air for various airflow lengths and mass flow rates. It was concluded that for the same airflow characteristics velocity of flow and air mass flow rate, SAH with a corrugated plate and double cover glass collector gave maximum efficiency. (Momin, Saini, and Solanki, 2002) used the impact of V-shaped ribs to formulate the correlations for friction factor (f) and nusselt number $(\mathrm{Nu})$, which can be used to select suitable roughness parameters to get optimal performance from solar air heater (SAH). (Moummi et al., 2004) experimented with rows of rectangular plate pins to enhance the thermal performance of a solar air heater. (Akpinar and Koçyiğit ,2010) used triangular-shaped, leaf-shaped, rectangular-shaped obstacles to investigate enhancement in performance of SAH to one having absorber plate with no obstacles. He concluded that the highest efficiency is achieved with leaf-based obstacles while the solar air heater with no obstacles gives the lowest one. (Bekele, Mishra, and Dutta, 2014) used delta-shaped obstacles and varied Reynolds number, relative obstacle height, longitudinal pitch, transverse pitch, and incidence angle and concluded that the obstacle's longitudinal pitch strongly affects the performance of SAH. (Ozgen, Esen, and Esen, 2009) experimented with double pass SAH with aluminum cans and observed that the use of aluminum cans enhances heat transfer rate. (Handoyo et al., 2014) observed improvement in the performance of SAH using a V-corrugated absorber plate along with obstacles mounted on the 
bottom plate. Obstacles were bent from $0^{\circ}$ to $80^{\circ}$ with an interval of $10^{\circ}$. Experimental tests indicated that obstacles mounted on the bottom plate at smaller angles resulted in higher air temperature and thermal efficiency. (Ansari and Bazargan, 2018) used a genetic algorithm, a search technique based on Darwin's theory of natural selection, to determine the optimum set of input parameters for SAH with a ribbed absorber plate. It was concluded that ribs increased thermal efficiency by $9 \%$ for low mass fluxes. (Moradi, Kianifar, and Wongwises, 2017) used Ansys Fluent software for optimizing design conditions. The present research investigates the improvement in thermal performance of a solar air heater (SAH) using triangular-shaped surface-mounted obstacles on the absorber plate. The mass flow rate (), heat flux, streamwise pitch, cross-stream pitch, the angle of inclination, the height of obstacles were chosen operating parameters while thermal efficiency, and pressure drop, $\Delta \mathrm{p}$ were chosen as performance parameters. Taguchi method was employed to determine an optimum set of operating parameters.

\section{SAH EXPERIMENTAL SET-UP}

$\mathrm{SAH}$ consists of the inlet region, test region, an outlet region (Figure 1). The test region is the main region where experiments are conducted. It is a wooden channel consisting of obstacles mounted absorber plate, heater, K-type thermocouples, etc. It is $25 \mathrm{~cm}$ in length, $30 \mathrm{~cm}$ in width $\& 5 \mathrm{~cm}$ in height. Inlet region and outlet region dimensions are chosen as per ASHRAE standards. The Inlet region is $80 \mathrm{~cm}$ in length, while the outlet region is $50 \mathrm{~cm}$ in length. Airflow through the setup is maintained by a blower. is measured by the mass flow meter and temperature determination is done by K-type thermocouples. The values of the parameters are Streamwise pitch $(\mathrm{Lx})=30-70 \mathrm{~mm}$, Cross streamwise pitch $(\mathrm{Ly})=56 \mathrm{~mm}-206 \mathrm{~mm}$, angle $(\Theta)=30^{\circ}-90^{\circ}$, height $(\mathrm{h})=22 \mathrm{~mm}-37.5 \mathrm{~mm}$ and mass flow rate ()$=0.01 \mathrm{~kg} / \mathrm{s}-0.02 \mathrm{~kg} / \mathrm{s}$.

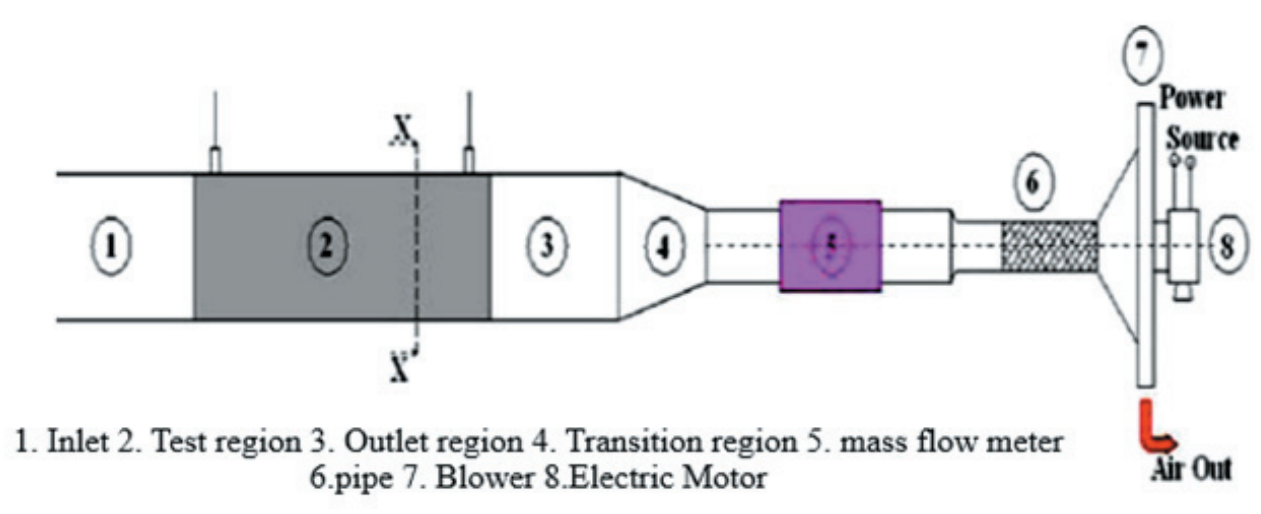

Figure 1. Schematic diagram of SAH

Triangular obstacles have been installed on absorber plate. Their function is to enhance the heat transfer rate between air and absorber plate by increasing the effective surface area of heat transfer and inducing turbulence inflow. The increase in heat transfer gets reflected in the thermal efficiency enhancement of the system. Figure 2 shows a typical triangular-shaped obstacle. 


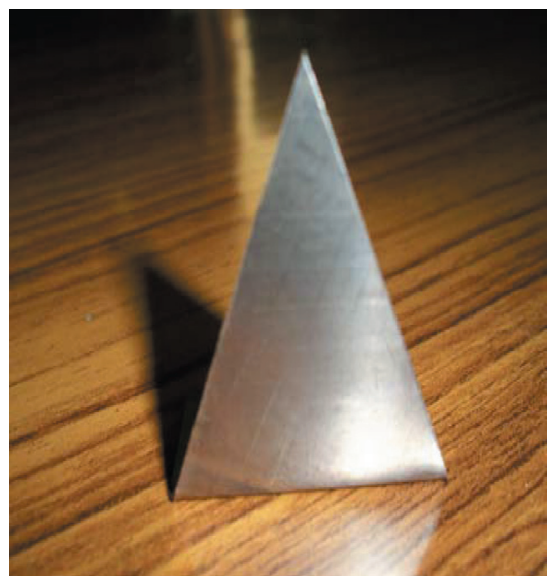

Figure 2. Triangular fin-shaped obstacle

\section{TAGUCHI ANALYTICAL METHOD}

Taguchi method is a well-established robust optimization technique. It minimizes the costs of experimentation by allowing a minimum number of experiments to see the effect of operating parameters on the target (Erbayrak and Erbayrak 2020, Mousa and Mjalli 2018). This experimental work is performed to optimize the output parameters like and $\Delta$ p. Taguchi method is adopted to see the impact of parameters and their possible mutual interactions in a lesser number of experimental data points.

\section{ORTHOGONAL ARRAY}

Six parameters and each parameter having three levels have been selected for the present work as shown in Table 1 (Hinislioğlu and Bayrak, 2004). The minimum number of experiments needed to be conducted based on the orthogonal array technique is 27 (for 6 parameters and 3 levels). To avoid or minimize sources of noise, the order of experiments to be done is made at random. These noise sources can come into play during experimentation and thus can adversely affect the results.

Table 1. Input Parameters

\begin{tabular}{|c|c|c|c|}
\hline Parameters & Level 1 & Level 2 & Level 3 \\
\hline A: $(\mathrm{kg} / \mathrm{s})$ & 0.01 & 0.02 & 0.03 \\
\hline B:Heat Flux $\left(\mathrm{W} / \mathrm{m}^{2}\right)$ & 600 & 700 & 800 \\
\hline C:Streamwise Pitch, $\mathrm{L}_{\mathrm{x}}(\mathrm{mm})$ & 30 & 45 & 70 \\
\hline D:Cross-stream Pitch, $\mathrm{L}_{\mathrm{y}}(\mathrm{mm})$ & 56 & 131 & 206 \\
\hline E:Angle, $\Theta$ & $30^{\circ}$ & $60^{\circ}$ & $90^{\circ}$ \\
\hline F:Height,h(mm) & 22 & 27.5 & 35 \\
\hline
\end{tabular}




\section{RESULTS AND DISCUSSIONS}

\section{DETERMINATION OF OPTIMUM WORKING CONDITIONS}

Table 2 represents the signal noise ratios corresponding to and $\Delta \mathrm{p}$. The smaller the better and nominal-the better are the optimization criteria for and $\Delta \mathrm{p}$ respectively.

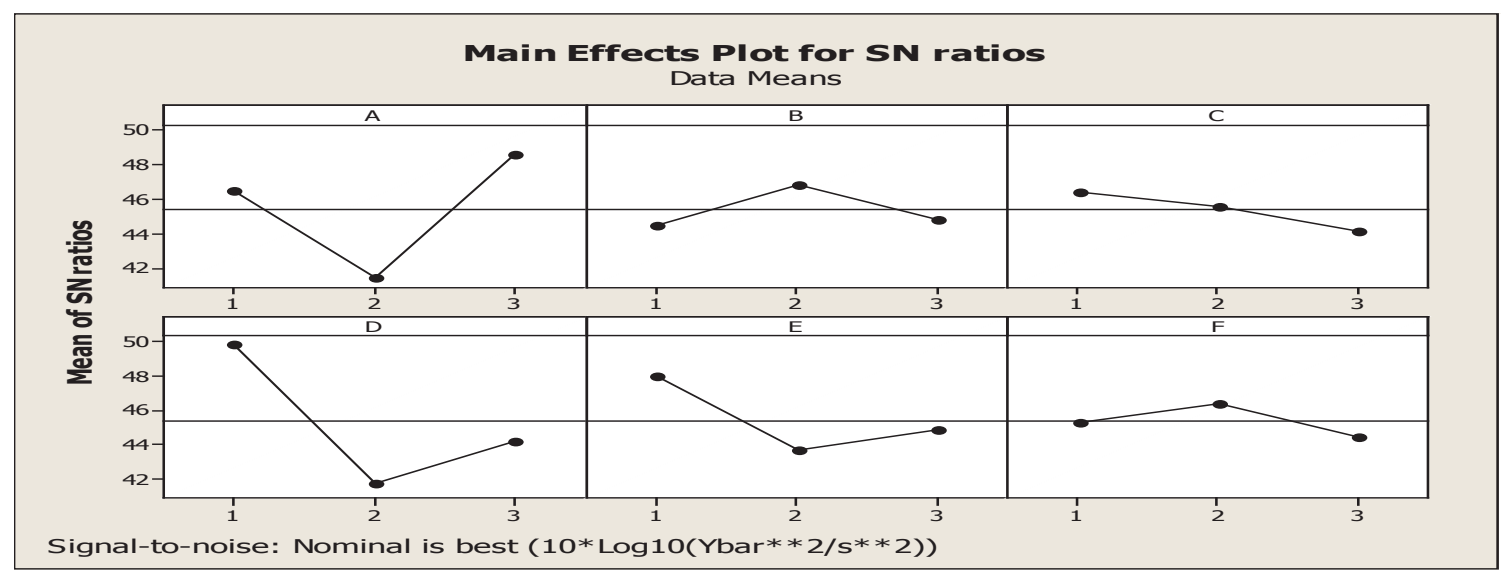

Figure 3. Main effects plot of thermal efficiency

Table $2 \mathrm{~S} / \mathrm{N}$ ratios for thermal efficiency, and pressure drop, $\Delta \mathrm{p}$.

\begin{tabular}{|c|c|c|}
\hline Experiment No. & S/N Ratio for thermal efficiency & S/N Ratio for pressure drop \\
\hline 1 & 48.0420 & -10.9222 \\
\hline 2 & 50.4295 & -7.2723 \\
\hline 3 & 49.5914 & -5.4608 \\
\hline 4 & 46.9256 & -6.0206 \\
\hline 5 & 44.1677 & -7.87195 \\
\hline 6 & 43.3296 & -8.36603 \\
\hline 7 & 45.6975 & -9.82723 \\
\hline 8 & 42.9396 & -9.93859 \\
\hline 9 & 42.1015 & -10.3703 \\
\hline 10 & 42.7238 & -11.5385 \\
\hline
\end{tabular}




\begin{tabular}{|c|c|c|}
\hline 11 & 36.8865 & -11.8213 \\
\hline 12 & 38.9961 & -11.8102 \\
\hline 13 & 49.3081 & -12.0412 \\
\hline 14 & 43.4708 & -12.4133 \\
\hline 15 & 45.5804 & -12.6189 \\
\hline 16 & 41.7484 & -13.5339 \\
\hline 17 & 35.9111 & -11.7092 \\
\hline 18 & 38.0207 & -10.7059 \\
\hline 19 & 43.7803 & -14.4032 \\
\hline 20 & 40.8907 & -14.2361 \\
\hline 21 & 43.1320 & -12.3400 \\
\hline 22 & 50.5671 & -12.5473 \\
\hline 23 & 47.6775 & -15.4903 \\
\hline 24 & 49.9187 & -15.6354 \\
\hline 25 & 53.3772 & -15.9107 \\
\hline 26 & 50.4877 & -16.1642 \\
\hline 27 & 52.7289 & -15.5992 \\
\hline
\end{tabular}

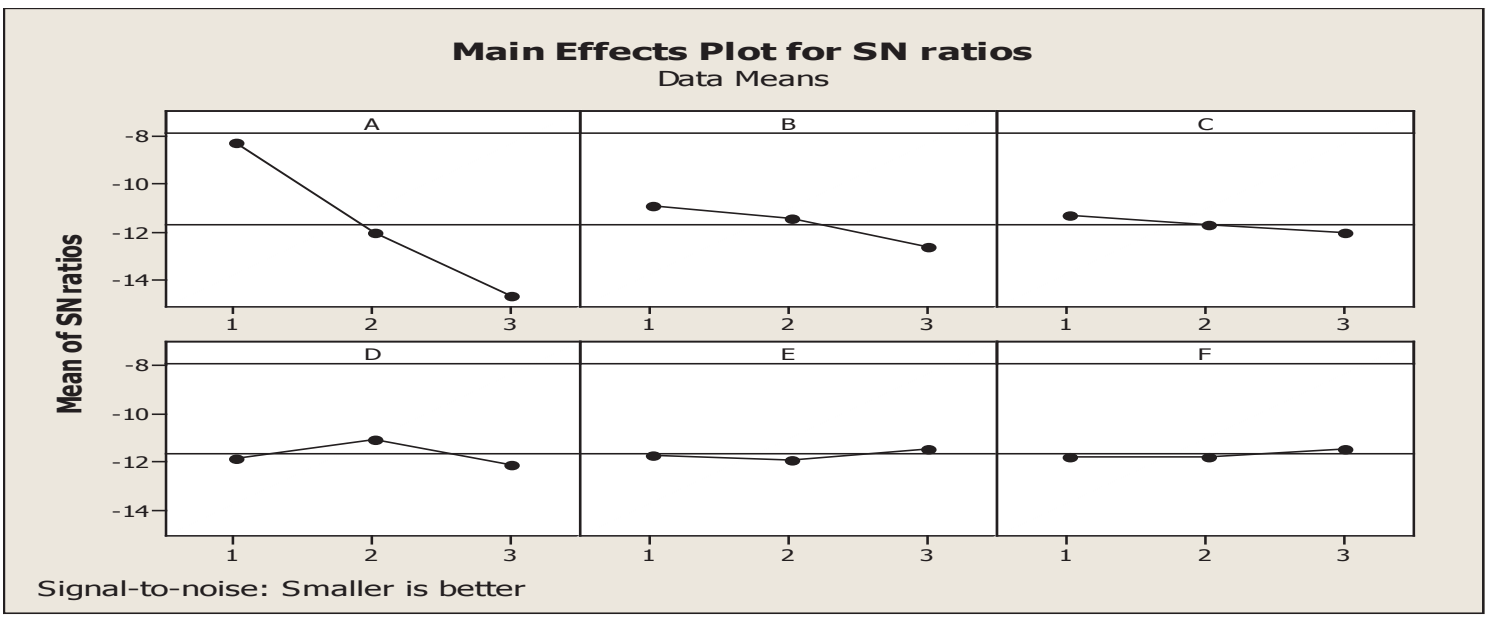

Figure 4. Main effects plot of Pressure Drop 
The influence of parameters on the thermal efficiency, and pressure drop, $\Delta \mathrm{p}$ is shown in figure 3 and 4 respectively. Experimental runs 1, 2, 3, 10, 11,12,18,19, and 21 correspond to the experiments in Table 2, for which column B is 1 . The first data point is the average of those obtained from the experiments with experiment runs 1, 2, 3, 10, 11,12,18,19, and 21. For the second data point, the experimental conditions are the conditions of the experiments with experiment numbers $4,5,6,13,14,15,20,22$, and 23) and so on. Data points determined by the above-mentioned procedure are given in table 3 for thermal efficiency and table 4 for pressure drop respectively.

Table 3. The mean Signal noise ratio effects of thermal efficiency

\begin{tabular}{|c|c|c|c|c|c|c|}
\hline Level & $\begin{array}{c}\text { A } \\
\text { (mass flow rate) }\end{array}$ & $\begin{array}{c}\text { B } \\
\text { (heat flux) }\end{array}$ & $\begin{array}{c}\text { C } \\
\text { (stream wise } \\
\text { pitch) }\end{array}$ & $\begin{array}{c}\text { D } \\
\text { (cross stream } \\
\text { pitch) }\end{array}$ & $\begin{array}{c}\text { E } \\
\text { (angle) }\end{array}$ & $\begin{array}{c}\text { F } \\
\text { (height) }\end{array}$ \\
\hline 1 & 46.49 & 44.48 & 46.34 & 49.80 & 47.94 & 45.27 \\
\hline 2 & 41.41 & 46.77 & 45.51 & 41.77 & 43.65 & 46.34 \\
\hline 3 & 48.60 & 44.78 & 44.14 & 44.17 & 44.82 & 44.40 \\
\hline
\end{tabular}

Table 4. The mean Signal noise ratio effects of pressure drop

\begin{tabular}{|c|c|c|c|c|c|c|}
\hline Level & $\begin{array}{c}\text { A } \\
\text { (mass flow rate) }\end{array}$ & $\begin{array}{c}\text { B } \\
\text { (heat flux) }\end{array}$ & $\begin{array}{c}\text { C } \\
\text { (stream wise } \\
\text { pitch) }\end{array}$ & $\begin{array}{c}\text { D } \\
\text { (cross stream } \\
\text { pitch) }\end{array}$ & $\begin{array}{c}\text { E } \\
\text { (angle) }\end{array}$ & $\begin{array}{c}\text { F } \\
\text { (height) }\end{array}$ \\
\hline 1 & -8.257 & -10.897 & -11.283 & -11.852 & -11.668 & -11.785 \\
\hline 2 & -12.021 & -11.445 & -11.678 & -11.021 & -11.880 & -11.752 \\
\hline 3 & -14.703 & -12.640 & -12.021 & -12.109 & -11.343 & -11.445 \\
\hline
\end{tabular}

\section{DETERMINATION OF THE OPTIMAL EXPECTED PERFORMANCE (EXP)}

The optimum conditions for Thermal efficiency are $\mathrm{A}_{3}, \mathrm{~B}_{2}, \mathrm{C}_{1}, \mathrm{D}_{1}$, and $\mathrm{E}_{1}$ and $\mathrm{F}_{2}$ [Figure 3]. The optimum conditions for pressure drop (smaller the better) are $\mathrm{A}_{3}, \mathrm{~B}_{3}, \mathrm{C}_{3}, \mathrm{D}_{3}, \mathrm{E}_{2}$, and $\mathrm{F}_{2}$ [Figure 4]. To validate the above-expected result (ExP), confirmation tests were carried out thrice at the above mentioned optimum set of input conditions. The conditions that correspond to the maximum thermal efficiency and the predicted performance are given in table 5. The conditions that correspond to the minimum pressure drop and the predicted pressure drop are given in table 5. 
Table 5. Conditions corresponding to the maximum thermal efficiency and prediction of performance

\begin{tabular}{|c|c|c|c|c|}
\hline \multirow{2}{*}{ Parameters } & \multicolumn{2}{|c|}{ Thermal efficiency } & \multicolumn{2}{|c|}{ Pressure drop } \\
\hline & Levels & $\begin{array}{c}\text { Contribution to } S / N \\
\text { Ratio (CR) }\end{array}$ & Levels & $\begin{array}{l}\text { Contribution to } \\
\text { S/N Ratio (CR) }\end{array}$ \\
\hline $\mathrm{A}()$ & 3 & 3.49 & 3 & -3.053 \\
\hline B (heat flux) & 2 & 1.66 & 3 & -0.99 \\
\hline $\mathrm{C}$ (stream wise pitch) & 1 & 1.23 & 3 & -0.371 \\
\hline D (cross stream pitch) & 1 & 4.69 & 3 & -0.459 \\
\hline E (angle) & 1 & 2.83 & 2 & -0.23 \\
\hline F (height) & 2 & 1.23 & 2 & -0.10 \\
\hline Net contribution of all parameters & & 9.98 & & -5.203 \\
\hline Mean performance value & & 45.11 & & -11.65 \\
\hline Optimal $\mathrm{S} / \mathrm{N}$ ratio & & 60.24 & & -16.85 \\
\hline $\begin{array}{c}\text { confidence interval } \\
\text { (@ } 95 \% \text { confidence level) }\end{array}$ & & $57.22-63.26$ & & 16 to -17.69 \\
\hline Confirmation test result (efficiency) & & 70.31 & & 5.6 \\
\hline
\end{tabular}

\section{CONCLUSION}

As per the above analysis, it is concluded that

- Efficiency is strongly affected by a cross-stream pitch then followed by mass flow rate, . Height and streamwise pitch have the least impact on efficiency.

- The height of obstacles and their angle affect pressure drop.

- For efficiency, the best combination is $\mathrm{A}_{3}$ (mass flow rate), $\mathrm{B}_{2}$ (heat flux), $\mathrm{C}_{1}$ (streamwise pitch), $\mathrm{D}_{1}$ (crossstream pitch), and $\mathrm{E}_{1}$ (angle), and $\mathrm{F}_{2}$ (height).

- For pressure drop, best combination is $\mathrm{A}_{3}$ (mass flow rate), $\mathrm{B}_{3}$ (heat flux), $\mathrm{C}_{3}$ (stream wise pitch), $\mathrm{D}_{3}$ (crossstream pitch), $E_{2}$ (angle) and $F_{2}$ (height). 


\section{REFERENCES}

A. Bekele, M. Mishra, and S. Dutta, "Performance characteristics of solar air heater with surface mounted obstacles," Energy Conversion and Management, vol. 85, pp. 603-611, 2014.

Abdul-Malik Ebrahim Momin, J.S. Saini, S.C. Solanki, "Heat Transfer and Friction in Solar Air Heater Duct with W-Shaped Rib Roughness on Absorber Plate.” International Journal of Heat and Mass Transfer, 3383-96, 2002.

C. Choudhury and H. P. Garg, "Design analysis of corrugated and flat plate solar air heaters," Renewable Energy, vol. 1, no. 5-6, pp. 595-607, 1991.

E. A. Handoyo, D. Ichsani, Prabowo, and Sutardi, "Experimental Studies on a Solar Air Heater Having V-Corrugated Absorber Plate with Obstacles Bent Vertically,"Applied Mechanics and Material, vol. 493, pp. 86-92, 2014.

E. K. Akpinar and F. Koçyiğit, "Experimental investigation of thermal performance of solar air heater having different obstacles on absorber plates," International Communication in Heat and Mass Transfer, vol. 37, no. 4, pp. 416-421, 2010.

Erbayrak, Seda, and Engin Erbayrak, "Determination of the Impact Damage Threshold Point of Composite Material Using Fuzzy-Base Taguchi Method.” Journal of Engineering Research, vol. 8, no. 3, 2020.

F. Ozgen, M. Esen, and H. Esen, "Experimental investigation of thermal performance of a double-flow solar air heater having aluminum cans," Renewable Energy, vol. 34, no. 11, pp. 2391-2398, 2009.

M. Ansari and M. Bazargan, “Optimization of Flat Plate Solar Air Heaters with Ribbed Surfaces," Applied Thermal Engineering, 2018.

Mousa, Hasan, and Farouq S. Mjalli, "Solar Water Desalination Using Plate-like Desalination Unit Enhanced by Air Flow." Journal of Engineering Research, vol. 6, no.2, pp. 1-12, 2018.

N. Moummi, S. Youcef-Ali, A. Moummi, and J. Y. Desmons, "Energy analysis of a solar air collector with rows of fins,” Renewable Energy, vol. 29, no. 13, pp. 2053-2064, 2004.

R. Moradi, A. Kianifar, and S. Wongwises, "Optimization of a solar air heater with phase change materials : Experimental and numerical study," Experimental Thermal and Fluid Science., 2017.

S. Hinislioğlu and O. Ü. Bayrak, "Optimization of early flexural strength of pavement concrete with silica fume and fly ash by the Taguchi method," Civil Engineering and Environmental Systems, vol. 21, no. 2. pp. 79-90, 2004. 